\title{
Influence of Organic Matter on Soil Hydrothermal Processes in the Tibetan Plateau: Observation and Parameterization?
}

\author{
Jing Sun, ${ }^{a}$ YingYing CHen, ${ }^{\mathrm{b}, \mathrm{c}}$ Kun YANG, ${ }^{\mathrm{a}, \mathrm{b}, \mathrm{c}}$ Hui Lu, ${ }^{\mathrm{a}}$ LONG ZHAO, ${ }^{\mathrm{d}}$ AND DONGHAI ZHENG ${ }^{\mathrm{b}}$ \\ ${ }^{a}$ Ministry of Education Key Laboratory for Earth System Modeling, Department of Earth System Science, Tsinghua University, \\ Beijing, China \\ ${ }^{\mathrm{b}}$ National Tibetan Plateau Data Center, Institute of Tibetan Plateau Research, Chinese Academy of Sciences, Beijing, China \\ ${ }^{\mathrm{c}}$ Center for Excellence in Tibetan Plateau Earth Sciences, Chinese Academy of Sciences, Beijing, China \\ ${ }^{\mathrm{d}}$ School of Geographical Sciences, Southwest University, Chongqing, China
}

(Manuscript received 26 March 2021, in final form 5 July 2021)

\begin{abstract}
In the central-eastern Tibetan Plateau (TP) there is abundant organic matter in topsoils, which plays a crucial role in determining soil hydraulic properties that need to be properly described in land surface models. Limited soil parameterizations consider the impacts of soil organic matter (SOM), but they still show poor performance in the TP. A dedicated field campaign is therefore conducted by taking undisturbed soil samples in the central TP to obtain in situ soil hydraulic parameters and to advance SOM parameterizations. The observed findings are twofold: 1) The SOM pore-size distribution parameter, derived from measured soil water retention curves, has been demonstrated to be much underestimated in previous studies. 2) SOM saturated hydraulic conductivity is overestimated. Accordingly, a new soil hydraulic parameterization is established by modifying a commonly used one based on observations, which is then evaluated by incorporating it into Noah-MP. Compared with the original ones, the new parameterization significantly improves surface soil liquid water simulations at stations with high surface SOM content, especially in the warm season. A further application with the revised Noah-MP indicates that SOM can enhance sensible heat flux but decrease evaporation and subsurface soil temperature in the warm season and tends to have a much weak effect in the cold season. This study provides insights into the role of SOM in modulating soil state and surface energy budget. Note that, however, there are many other factors at play and the new parameterization is not necessarily applicable beyond the TP.
\end{abstract}

KEYWORDS: Soil moisture; Soil temperature; Surface fluxes; Measurements; Parameterization

\section{Introduction}

The Tibetan Plateau (TP) is one of the regions with rich soil organic matter (SOM), but SOM in this area mainly exists in the topsoil and is distinct from that in the high latitudes of the Northern Hemisphere. Meanwhile, there is significant spatial heterogeneity in SOM content in the TP: high in the centraleastern part of the plateau but low in other regions (Shangguan et al. 2014; Zhang et al. 2021). The central-eastern TP is mainly covered by alpine meadows and its climate is cold (which leads to the slow decomposition of SOM), thus resulting in the accumulation of abundant organic matter and dense roots in topsoils.

Compared with mineral soils, pure organic matter exhibits quite different hydrothermal characteristics: generally higher porosity, hydraulic conductivity, and heat capacity, as well as lower thermal conductivity and water potential (Letts et al. 2000; Lawrence and Slater 2008). The presence of large amounts of SOM and roots in the central-eastern TP exerts significant impacts on soil hydrothermal properties (Yang et al. 2005; Chen et al. 2012; Zheng et al. 2015a,b), which could affect

Supplemental information related to this paper is available at the Journals Online website: https://doi.org/10.1175/JHM-D-210059.s1.

Corresponding authors: Kun Yang, yangk@tsinghua.edu.cn; Yingying Chen, chenyy@itpcas.ac.cn land-atmosphere interactions. But it is difficult to measure soil hydraulic properties or parameters, which are thus often estimated using pedotransfer functions (PTFs). The PTFs used in most current land surface models (LSMs) mainly take soil type or texture (sand, clay, and silt content; Cosby et al. 1984) as inputs and rarely consider the influence of SOM.

Previous studies have suggested severe underestimation of topsoil moisture in the central-eastern TP by neglecting SOM in LSMs (Yang et al. 2009; Chen et al. 2013). In recent years, large efforts have been made to address this issue. Several LSMs in later releases have tried to consider SOM effects on soil hydrothermal parameterizations, despite some problems in reproducing real physical processes. Moreover, various experiments have been conducted to study these effects using different LSMs. Based on Noah LSM, Zheng et al. (2015a,b) explored SOM effects on soil hydrothermal properties using observations from Maqu - a typical humid area located in the eastern TP-and found that the SOM effects on soil moisture were greater than those on soil temperature. Recently, Zhang et al. (2020) systematically evaluated commonly used schemes for predicting soil hydraulic parameters, indicating that soil hydraulic parameterizations considering SOM effects greatly reduced simulated soil moisture errors. Despite these studies suggest that the inclusion of SOM effects can significantly improve the simulations, there remain a few studies showing negligible impacts. Gao et al. (2015) evaluated the soil hydraulic parameterization proposed by Lawrence and Slater (2008) based on the Noah LSM with multiparameterization 
options (Noah-MP) using observations at a site in the central $\mathrm{TP}$, yet no significant improvement in simulated topsoil moisture was seen with the consideration of layered organic matter effects. This is probably because that the SOM parameters of Arctic implemented by Lawrence and Slater (2008) are not necessarily applicable to the TP. In addition, Sun et al. (2016) found that soil moisture simulations in the northeastern TP were insensitive to SOM using the original soil parameterization in the Dynamic Land Model (version 1.0), yet obvious correlation could be seen between soil moisture and SOM content through their modified scheme. Overall, there are divergent opinions on the SOM effects on soil moisture, with most believing them remarkable. Since soil moisture acts as a link between surface water, groundwater, and atmospheric water, it is of great importance to further explore SOM effects on it.

Indeed, existing SOM parameterizations are subject to a series of problems in terms of applicability and reliability. The uncertainties of soil hydraulic parameterizations can lead to biased model simulations, which indicates that these parameterizations require further investigation and evaluation prior to practical applications. For instance, values of SOM hydraulic parameters were empirically determined from the literature and rarely supported by observations in the past. These studies, while recognizing the importance of SOM, have mainly focused on its qualitative effects on soil porosity, saturated hydraulic conductivity, and water potential, with less attention paid to the underlying mechanisms. Little is known about how and why SOM influences the soil pore-size distribution parameter $b$, how important the SOM effect on each soil hydraulic parameter is for improving soil moisture simulations, and so on.

In this study, we investigate the SOM effects on soil hydraulic properties based on in situ observations of soil texture and organic matter content, soil water retention curves, saturated hydraulic conductivity as well as soil moisture/temperature in the Naqu region of the central TP. Our objectives are 1) developing a new observation-based soil hydraulic scheme considering SOM and 2) testing it with the Noah-MP. The paper is structured as follows: Section 2 describes the study region, the Noah-MP LSM, and data used in this study. Section 3 introduces three reference soil hydraulic parameterizations, and details SOM hydraulic parameters obtained from the observations, based on which a new hydraulic parameterization is proposed. Section 4 evaluates the effects of these soil parameterizations on soil moisture and temperature simulations. Section 5 further discusses the impacts of SOM hydrothermal properties on soil state and land fluxes, followed by a summary and outlook in section 6 .

\section{Data and model}

\section{a. Study region and in situ data}

As mentioned above, the topsoil of the central-eastern TP is rich in organic matter (Fig. 1a). The source of SOM data is from a global high-resolution dataset of sand, clay, and SOM (Dai et al. 2019a,b; hereafter referred as Dai's dataset). To investigate SOM characteristics on the TP, we conducted a dedicated experiment to obtain soil water retention curves in the Naqu region (roughly $30.5^{\circ}-33.0^{\circ} \mathrm{N}, 90.5^{\circ}-92.5^{\circ} \mathrm{E}$ ). In this region, the in situ data of soil moisture and temperature were also collected. As shown in Fig. 1, there are 9 soil water retention curve stations (Fig. 1b) and 56 soil moisture/temperature stations (Fig. 1c).

The Naqu region has a moderate topography with gentle slopes and hills in a cold and semiarid climate. The average annual air temperature is below $0^{\circ} \mathrm{C}$ and the annual precipitation is about $400-500 \mathrm{~mm}$, concentrated in June to September. Most of the area is covered by alpine meadows with a canopy height of several centimeters throughout the growing season. The vegetation is sparse and dwarf, and often in scattered patches. This region is also characterized by abundant humus that accumulates in topsoils, and therefore possesses high and stable SOM content. The majority of the soil is seasonally frozen.

\section{1) SOIL WATER RETENTION CURVE AND SATURATED HYDRAULIC CONDUCTIVITY}

Observations on soil water retention curve and saturated hydraulic conductivity are usually scarce due to the high cost and time-consuming nature of such measurements. We collected valuable observations of soil water retention curves at nine experimental stations in the Naqu region (named D110, Noda, Amdo, MS3478, BJ, MS3608, ANNI, MS3637, and Namco; Fig. 1b). These stations are from Coordinated Enhanced Observing Period Asia-Australia Monsoon Project-Tibet (CAMP-Tibet; Koike 2004), except Namco station maintained by the Institute of Tibetan Plateau Research of Chinese Academy of Sciences (Ma et al. 2008). The altitudes of these stations vary between 4480 and $4985 \mathrm{~m}$, and the vegetation type is either alpine meadow or grassland. When sampling, the cutting ring soil augers made by Nanjing Soil Instrument Factory Company, Ltd., were used in order to not disturb the soil structure. The auger is equipped with two 1-cm-long cutting rings (one for soil water retention curve measurement and the other for soil texture and SOM mass content measurement) and one 5 -cm-long cutting ring (for soil porosity measurement). At each station, 1-4 undisturbed soil samples were first taken near 10-, 20-, 30-, 40-, and 50-cm depths during the field campaign. Then the corresponding soil water contents at different pressures were measured in the laboratory with 15 Bar Pressure Membrane Instruments made by Soilmoisture Equipment Corp., resulting in a total of 74 soil water retention curves (Table S1 in the online supplemental material). Meanwhile, soil saturated hydraulic conductivity, soil texture, organic matter content and the porosity were also measured at the nine stations as well as the Tanggula station. In particular, SOM mass content was measured by the total organic carbon (TOC) analyzers (Shimadzu TOC-VCPH), and soil texture was measured with a laser particle size analyzer made by Microtrac, Inc., after removal of SOM. Note that 1) prior to the above measurements, soil samples were preprocessed by removing as much of visible soil roots as possible, and 2) since the TOC analyzers actually measured soil organic carbon (SOC), the mass content of SOM was obtained by multiplying the carbon content by the van Bemmelen factor of 1.724 . 

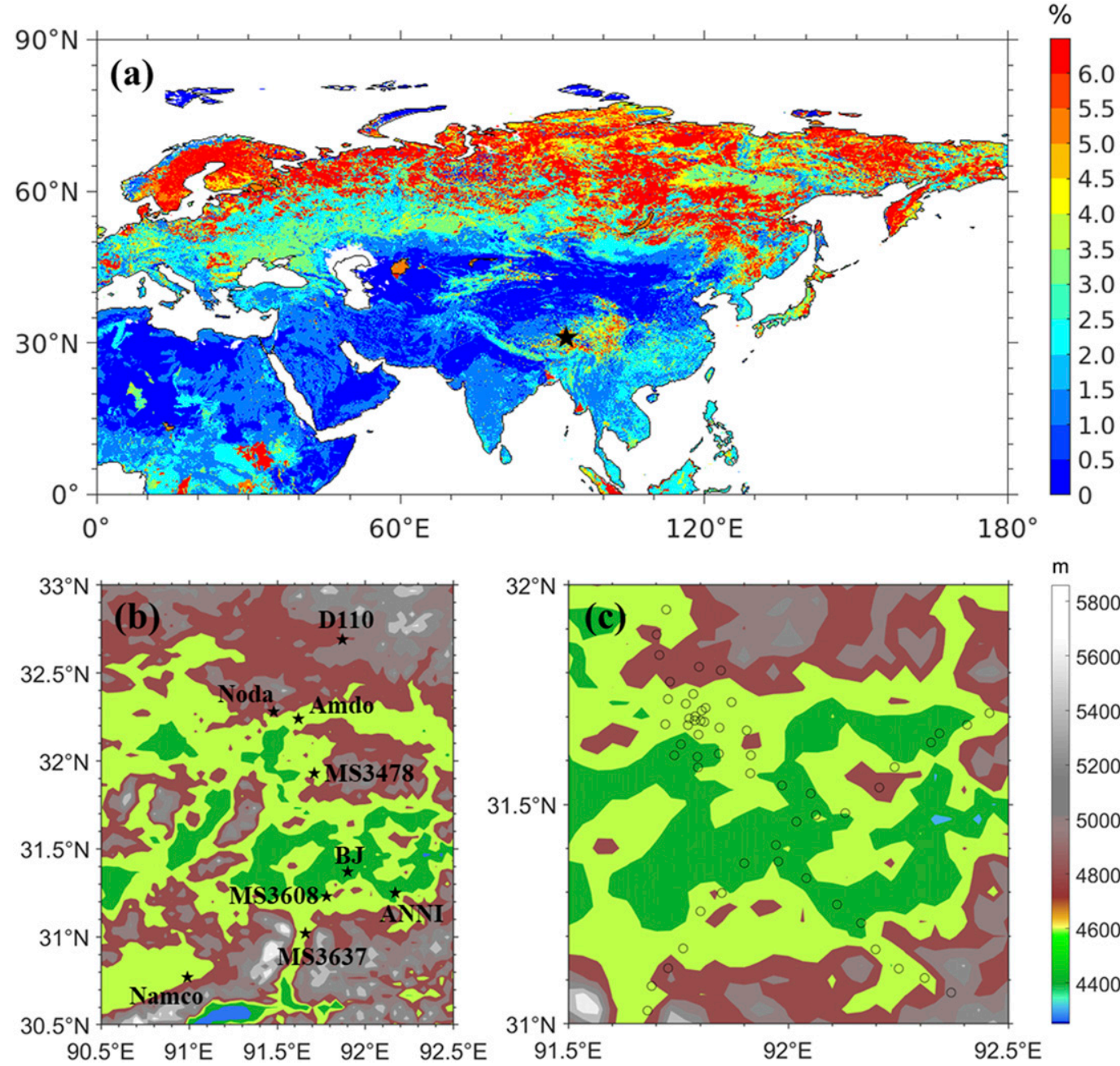

FIG. 1. (a) Spatial patterns of surface $(0-10 \mathrm{~cm})$ SOM mass content. The SOM content data are from Dai et al. (2019a,b). The black star denotes the Naqu region. (b),(c) Locations of the two measuring networks in the Naqu region. Stars and circles denote the soil water retention curve in (b) and soil moisture/temperature stations in (c), respectively. All the stations have measured data of SOM mass content.

Vertical profiles of SOM mass content at these soil water retention curve stations are shown in Fig. 2. It can be seen that the SOM content varies from $0 \%$ to $6 \%$ at all stations except for MS3478 and Noda stations, where the SOM content is larger than $18 \%$ at depths of 10 and $20 \mathrm{~cm}$. The overall high SOM content at Noda station is probably because it is located in a wetland and thus has accumulated significant SOM. In general, the SOM content decreases with increasing depth. Moreover, although Dai's dataset performs well at the gridded scale, discrepancies are observed when compared with sitescale measurements (Fig. 2).

\section{2) SOIL MOISTURE AND TEMPERATURE}

The soil moisture and temperature data used in this study are obtained from the multiscale Soil Moisture and Temperature Monitoring Network in the central TP (Yang et al. 2013; Zhao et al. 2013). This network consists of 56 stations, all of which are deployed on grasslands (Fig. 1c). Both the EC-TM and 5TM capacitance probes made by Decagon (now Meter), United States (https://www.metergroup.com), were used to measure soil moisture/temperature with an accuracy of $\pm 0.02 \mathrm{~m}^{3} \mathrm{~m}^{-3} / \pm 1^{\circ} \mathrm{C}$ and resolution of $0.001 \mathrm{~m}^{3} \mathrm{~m}^{-3} / 0.1^{\circ} \mathrm{C}$ for mineral soil. Since the sensors measure soil moisture based on the relationship between soil dielectric permittivity and the liquid water, which may be changed by SOM, the measured soil moisture values were calibrated through laboratory experiments as detailed in Yang et al. (2013). Soil moisture and temperature profiles were measured at depths of $0-5,10,20$, and $40 \mathrm{~cm}$ with a temporal resolution of $30 \mathrm{~min}$, and the corresponding soil texture and organic matter content were also retrieved at these stations.

During the construction and maintenance of this network, dataloggers at some stations were damaged and then replaced with new instruments, resulting in some gaps in recorded soil temperature/moisture. Figure S1 shows the temporal coverages of data and missing information for each station. The time period of interest in this study is 

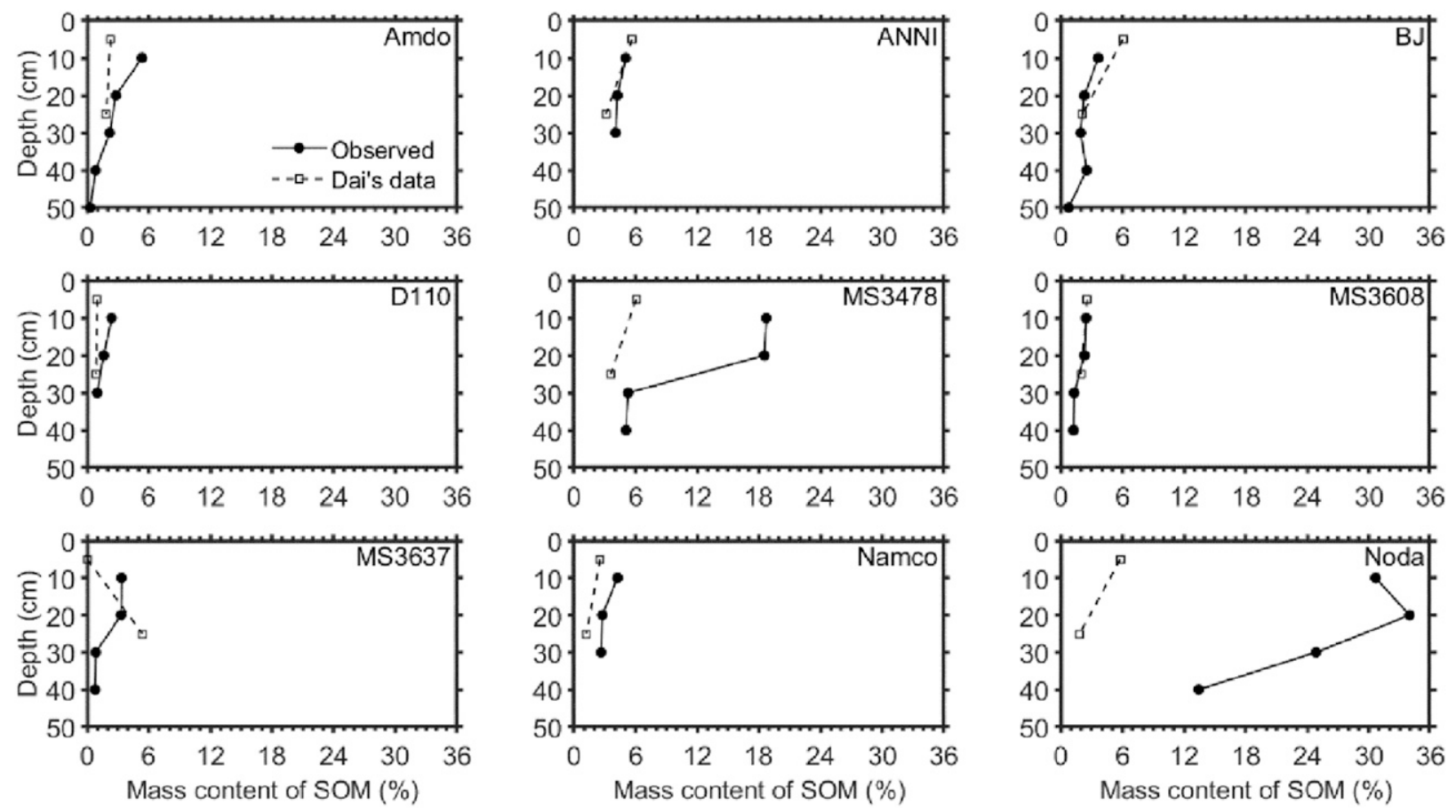

FIG. 2. Vertical profiles of SOM mass content at the nine stations with soil water retention measurements, sourcing from observations and Dai's dataset.

2011-17. To eliminate the mismatch in vertical representativeness between the measurements and LSM simulations, the measurements are first aggregated into surface $(0-10 \mathrm{~cm})$ and subsurface $(10-40 \mathrm{~cm})$ layer averages using Eqs. (1)-(4), which are then compared with LSM simulations at corresponding layers. Note that, assuming soil moisture/temperature to linearly vary with depth between two adjacent observation depths, the average soil moisture/temperature in each soil layer $(0-10$ and $10-40 \mathrm{~cm})$ can be calculated by weighting observations at the depths of $0-5,10,20$, and $40 \mathrm{~cm}$, so the coefficients (i.e., weights) preceding observations at different depths are not necessarily equal:

$$
\begin{aligned}
& \mathrm{SX}_{0-10}=\frac{3 \mathrm{SX}_{0-5}+\mathrm{SX}_{10}}{4}, \text { and } \\
& \mathrm{SX}_{10-40}=\frac{\mathrm{SX}_{10}+3 \mathrm{SX}_{20}+2 \mathrm{SX}_{40}}{6},
\end{aligned}
$$

where $\mathrm{SX}_{0-5}, \mathrm{SX}_{0-10}$, and $\mathrm{SX}_{10-40}$ denote the average soil moisture/temperature at the depths of $0-5,0-10$, and 10 $40 \mathrm{~cm}$, respectively; $\mathrm{SX}_{10}, \mathrm{SX}_{20}$, and $\mathrm{SX}_{40}$ denote the soil moisture/temperature at the depths of 10,20 , and $40 \mathrm{~cm}$, respectively.

$$
\begin{aligned}
M_{X}^{0-10} & =\frac{M_{X}^{0}+2 M_{X}^{5}+M_{X}^{10}}{4}, \text { and } \\
M_{X}^{10-40} & =\frac{M_{X}^{10}+2 M_{X}^{20}+2 M_{X}^{30}+M_{X}^{40}}{6},
\end{aligned}
$$

where $M_{X}^{0-10}$ and $M_{X}^{10-40}$ are the average mass content of sand/clay/SOM at the depths of $0-10$ and $10-40 \mathrm{~cm}$, respectively; $M_{X}^{0}, M_{X}^{5}, M_{X}^{10}, M_{X}^{20}, M_{X}^{30}$, and $M_{X}^{40}$ are the sand/clay/SOM mass content at the depths of $0,5,10,20,30$, and $40 \mathrm{~cm}$, respectively.

Figure 3a presents spatial distributions of measured SOM content at the 56 stations. In the surface layer [Fig. 3a(1)], it can be seen that SOM content in 16 of the stations exceeds $6 \%, 20$ stations between $4 \%$ and $6 \%$, and the remaining 20 stations less than $4 \%$. This fully reveals the large spatial heterogeneity of SOM, and thus gridded data of surface SOM content obtained by direct spatial interpolation using limited samples (such as Dai's dataset) is likely to cause large uncertainties in this region [Fig. 3b(1)]. By contrast, the spatial heterogeneity in SOM content almost disappears in the subsurface layer [Fig. 3a(2)], with 47 stations less than 4\%, 3 stations between $4 \%$ and $6 \%$, and only 1 station above $6 \%$ (SOM content data unavailable at the remaining 5 stations). That said, Dai's data can reasonably represent subsurface SOM content in this region [Fig. 3b(2)].

According to the mass content of surface SOM, the 56 stations in Naqu can be divided into three classes (low: $\leq 4 \%$; middle: $4 \%-6 \%$; high: $\geq 6 \%$ ). Observed seasonal variations of soil liquid water content at different depths are given in Fig. 4. Obviously, for stations with high surface SOM content, soil liquid water content at the depth of $0-5 \mathrm{~cm}$ exhibits the largest value and amplitude $\left(0.12-0.40 \mathrm{~m}^{3} \mathrm{~m}^{-3}\right)$, followed by that at 10-, then 20- and 40-cm depths (Fig. 4a). When the surface SOM content is middle, the liquid water content exhibits similar features (Fig. 4b): reaches its maximum at $0-$ 5-cm depth and then decreases with depth, but the amplitude of the topsoil water content $\left(0.09-0.32 \mathrm{~m}^{3} \mathrm{~m}^{-3}\right)$ is smaller 

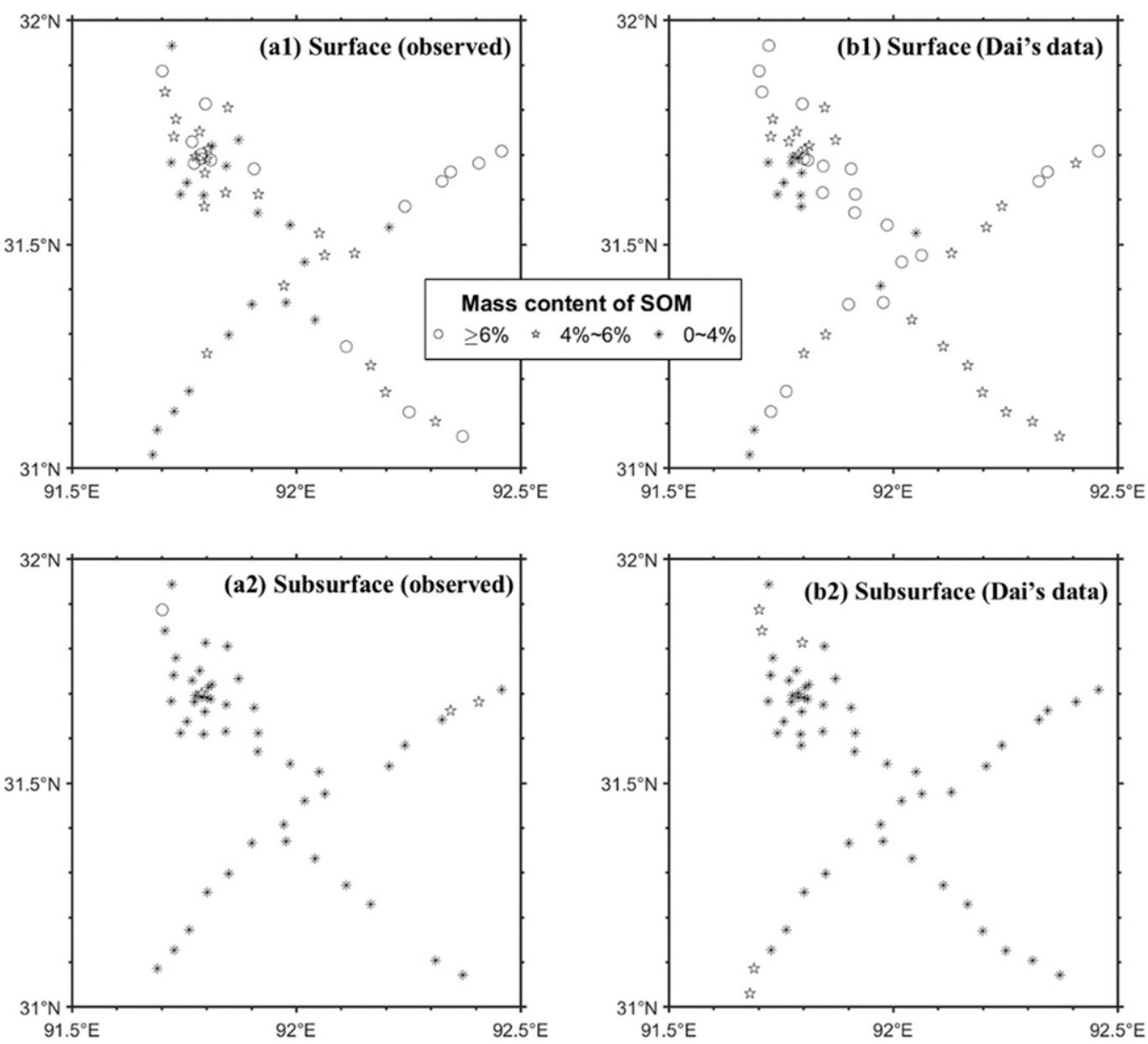

FIG. 3. Spatial patterns of surface $(0-10 \mathrm{~cm})$ and subsurface $(10-40 \mathrm{~cm}) \mathrm{SOM}$ mass content at the 56 soil moisture/temperature stations, sourcing from (a1),(a2) observations and (b1),(b2) Dai's dataset.

than that at stations with high surface SOM content. It is obvious that the liquid water contents at depths of $0-5$ and $10 \mathrm{~cm}$ at stations with middle surface SOM content are lower than those at stations with high surface SOM content (Fig. 4a), especially in summer. The differences in soil liquid water content at different depths are relatively slight in winter. For stations with low surface SOM content, the amplitude in topsoil liquid water content is the smallest, only $0.06-0.24 \mathrm{~m}^{3} \mathrm{~m}^{-3}$, and the differences between the depths are small throughout the year (i.e., the vertical heterogeneity almost disappears). Moreover, soil liquid water content at the depths of $0-5$ and $10 \mathrm{~cm}$ is much lower than that at stations with mid-high surface SOM content. This is consistent with the result found by Luo et al. (2020) that the SOM content is positively correlated with soil water content in summer. Moreover, the variability within different SOM classes is reasonably smaller than that between these classes (Fig. S2). In general, it can be concluded that the SOM content has a crucial impact on soil liquid water content in the warm season (May-October), while the influence in the cold season (January-April, November, and December) is relatively small. In addition, for stations with high surface SOM content, the liquid water content exhibits evident vertical heterogeneity, which disappears gradually with the decrease of surface SOM content.

\section{b. Model and inputs}

The land surface model used in this study is the Noah-MP, which is a community model with the advantage of providing several schemes for each physical process (Niu et al. 2011) and has been widely used in the study of regional climate. The combinations of schemes we selected are listed in Table 1 . The offline version of the Noah-MP model used in this study has been incorporated into the High-Resolution Land Data Assimilation System (HRLDAS, version 4.0.1). This model divides the soil into four layers, which are 0-10-, 10-40-, 40-100-, and 100-200-cm depths. Since the available observations are mainly measured at the depth of $0-40 \mathrm{~cm}$, subsequent analyses only focus on simulations of the top two layers (i.e., surface and subsurface layers). Our simulation period is $2000-17$ with $2000-10$ for model spinup, and 2011-17 for analysis.

The meteorological forcing data are from the high-resolution China Meteorological Forcing Dataset (CMFD) (Yang and He 2011; He et al. 2020). This dataset covers the period 1979-2018 with a temporal resolution of $3 \mathrm{~h}$ and a spatial resolution of $0.1^{\circ}$, 

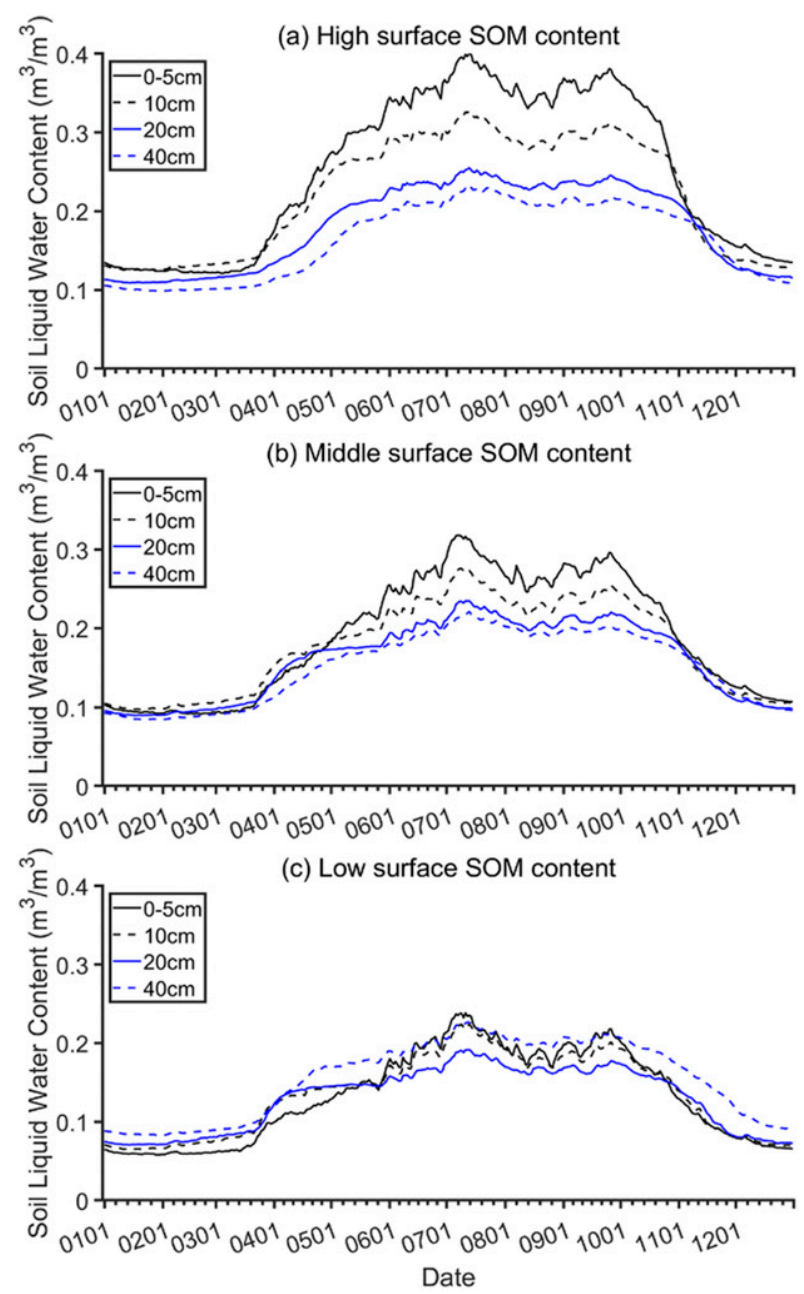

FIG. 4. Seasonal variations of observed multiyear mean (201117) soil liquid water content at the depths of $0-5,10,20$, and $40 \mathrm{~cm}$ for the 56 soil moisture/temperature stations divided into three classes: (a) high, (b) middle, and (c) low according to mass content of SOM.

and consists of seven variables including downward shortwave radiation, downward longwave radiation, surface air pressure, 2-m air temperature, 2-m specific humidity, 10-m wind speed, and precipitation. The CMFD data have been widely used in water cycle and land surface processes studies in China (e.g., Sun et al. 2020; Dai et al. 2020).

For layered soil data, measured sand, clay, and SOM content data at the depths of $0-10$ and $10-40 \mathrm{~cm}$ are utilized. Given the lack of observations at the depths of 40-100 and $100-200 \mathrm{~cm}$, Dai's dataset is adopted as a surrogate. Other input data required by the model are derived from static data in the Weather Research and Forecasting (WRF) system.

\section{Observations and parameterizations on soil hydraulic properties}

In this section, three existing soil hydraulic schemes are first introduced with two already incorporated into the Noah-MP
LSM and one widely used for other TP land surface simulations, and all of them act as reference. Then soil hydraulic parameters of organic matter are derived and analyzed based on observations, and accordingly a new soil hydraulic scheme is proposed.

\section{a. Reference soil hydraulic parameterizations}

The soil hydraulic parameterizations of interest in this study are the schemes of Default (lookup-table-based and Noah-MP default), SR06 (Saxton and Rawls 2006) and LS08 (Lawrence and Slater 2008). The Noah-MP default scheme is a commonly used one, which classifies soils into several types without considering SOM and soil vertical heterogeneity. The soil data adopted in the default scheme originated from the hybrid State Soil Geographic/Food and Agriculture Organization of the United Nations (STATSGO/FAO) soil dataset (FAO 1971, 1974, 1975a,b, 1977a,b, 1978a,b, 1979, 1981, 1991) at a resolution of 30 arc s. In this scheme, each soil type corresponds to a prescribed set of hydraulic parameter values. Obviously, one soil type can correspond to various sand, silt, and clay contents, and thus a wide range of soil hydraulic parameters, so the default scheme can lead to large uncertainties when compared with in situ data.

The SR06 scheme, which was proposed by Saxton and Rawls (2006), has been newly introduced into Noah-MP but is rarely used. In addition, we noticed that the required input of SOM content for the SR06 scheme was hard coded as 0.0 in the model. We have modified this part so that the model can use SOM content data. In addition, the LS08 scheme, which was proposed by Lawrence and Slater (2008), has been applied to soils with high SOM content (e.g., Chen et al. 2012; Zheng et al. 2015a). These two schemes describe the influence of SOM in different ways and are used for comparison to assess the rationality of different descriptions of soil hydraulic properties. The SR06 scheme takes the soil as a mixture of sand, clay, silt, and organic matter. More details of the scheme are documented in Saxton and Rawls (2006). In the LS08 scheme, the soil is assumed to be a combination of mineral soil and organic matter, and soil hydraulic properties are weighted by their volumetric content, as below:

$$
\begin{aligned}
\theta_{s} & =\left(1-V_{\mathrm{SOM}}\right) \times \theta_{s, \text { min }}+V_{\mathrm{SOM}} \times \theta_{s, \mathrm{SOM}}, \\
\theta_{s, \text { min }} & =0.489-0.00126 \times(\% \text { sand }), \\
b & =\left(1-V_{\mathrm{SOM}}\right) \times b_{\min }+V_{\mathrm{SOM}} \times b_{\mathrm{SOM}}, \\
b_{\text {min }} & =2.91+0.159 \times(\% \text { clay }), \\
\psi_{s} & =\left(1-V_{\mathrm{SOM}}\right) \times \psi_{s, \text { min }}+V_{\mathrm{SOM}} \times \psi_{s, \mathrm{SOM}}, \\
\psi_{s, \text { min }} & =-10.0 \times 10^{1.88-0.0131(\% \mathrm{sand})}, \\
K_{s} & =\left(1-V_{\mathrm{SOM}}\right) \times K_{s, \text { min }}+V_{\mathrm{SOM}} \times K_{s, \mathrm{SOM}}, \\
K_{s, \text { min }} & =7.0556 \times 10^{-6.884+0.0153(\% \mathrm{sand})}, \quad \text { and } \\
V_{\mathrm{SOM}} & =\frac{\rho_{P}\left(1-\theta_{s, \text { min }}\right) M_{\mathrm{SOC}}}{\rho_{\mathrm{SOC}}\left(1-M_{\mathrm{SOC}}\right)+\rho_{P}\left(1-\theta_{s, \text { min }}\right) M_{\mathrm{SOC}}},
\end{aligned}
$$


TABLE 1. Options of the Noah-MP physical processes schemes used in this study.

\begin{tabular}{ll}
\hline \multicolumn{1}{c}{ Physical processes } & \multicolumn{1}{c}{ Options } \\
\hline Vegetation model (VEG) & 1: Table LAI, use vegetation fraction from input \\
Canopy stomatal resistance (CRS) & 2: Jarvis (Jarvis 1976) \\
Soil moisture factor for stomatal & 2: CLM (Oleson et al. 2004) \\
$\quad$ resistance (BTR) & 1: TOPMODEL with groundwater (Niu et al. 2007) \\
Runoff and groundwater (RUN) & 1: M-O (Brutsaert 1982) \\
Surface-layer drag coefficient (SFC) & 1: NY06 (Niu and Yang 2006) \\
Super-cooled liquid water (FRZ) & 1: NY06 (Niu and Yang 2006) \\
Frozen soil permeability (INF) & 3: two-stream applied to vegetated fraction (gap $=$ \\
Canopy gap for radiation transfer (RAD) & 1-FVEG) \\
Snow surface albedo (ALB) & 2: CLASS (Verseghy 1991) \\
Precipitation partition (SNF) & 2: BATS: $T_{\text {sfc }}<T_{\text {frz }}+2.2 \mathrm{~K}$ \\
Lower boundary of soil & 2: Soil temperature at 8-m depth \\
$\quad$ temperature (TBOT) & 2: Full implicit (original Noah); temperature top \\
Snow/soil temperature time & boundary condition \\
$\quad$ scheme (STC) &
\end{tabular}

where $\theta_{s}, K_{s}, \psi_{s}$, and $b$ are the soil porosity $\left(\mathrm{m}^{3} \mathrm{~m}^{-3}\right)$, saturation hydraulic conductivity $\left(\mathrm{m} \mathrm{s}^{-1}\right)$, saturation water potential $(\mathrm{m})$, and pore-size parameter (unitless), respectively; $K_{s, \text { min }}$ and $K_{s, \mathrm{SOM}}$ are the saturation hydraulic conductivity $\left(\mathrm{m} \mathrm{s}^{-1}\right)$ of mineral soil and organic matter $\left(1.0 \times 10^{-4}\right)$, respectively; $\psi_{s, \text { min }}$ and $\psi_{s, \text { SOM }}$ are the water potential $(\mathrm{m})$ of mineral soil and organic matter $(-0.0103)$ at air entry, respectively; $b_{\min }$ and $b_{\mathrm{SOM}}$ are the pore-size distribution parameter (unitless) of mineral soil and organic matter $(2.7)$, respectively; $\theta_{s, \min }$ and $\theta_{s, \mathrm{SOM}}$ are the porosity $\left(\mathrm{m}^{3} \mathrm{~m}^{-3}\right)$ of mineral soil and organic matter $(0.9)$, respectively; \%sand and \%clay are the mass percentage (\%) of sandy and clay after removing SOM, respectively; $V_{\text {SOM }}$ is the volume content of organic matter; $\rho_{P}$ and $\rho_{\text {SOC }}$ are the density of mineral soil $\left(2700 \mathrm{~kg} \mathrm{~m}^{-3}\right)$ and organic carbon $\left(130 \mathrm{~kg} \mathrm{~m}^{-3}\right)$, respectively; $M_{\mathrm{SOC}}$ is the organic carbon mass content $\left(\mathrm{kg} \mathrm{kg}^{-1}\right)$.

\section{b. A new observation-based soil hydraulic parameterization}

Letts et al. (2000) determined hydraulic parameters for three SOM classes (fibric, hemic, and sapric peat) from the literature, and found that the values of $b_{\mathrm{SOM}}$ and $K_{s, \mathrm{SOM}}$ varied considerably with the degree of decomposition/humification while those of $\theta_{s, \text { SOM }}$ and $\psi_{s \text {,SOM }}$ were relatively stable. This indicates that the quality of SOM has a large influence on the parameters in the LS08 scheme, so these parameter values need to be carefully described according to soil characteristics in a specific study region.

\section{1) OBSERVED SOM PORE-SIZE DISTRIBUTION PARAMETER}

The parameter $b$ is an empirical parameter reflecting the distribution of pore size in the soil column (Clapp and Hornberger 1978). In previous studies, the value of the SOM parameter $b_{\text {SOM }}$ was usually determined upon its ability in capturing observations through model simulation. Letts et al. (2000) gave representative $b_{\text {SOM }}$ values for the three coarsely divided classes as $2.7,6.1$, and 12.0, respectively. Lawrence and Slater (2008) took $b_{\text {SOM }}$ as 2.7 directly when characterizing Arctic SOM, and Zheng et al. (2015a) took $b_{\mathrm{SOM}}=12.0$ which was the maximum value recorded in Letts et al. (2000) when studying Tibetan soil characteristics in the Maqu region. This determination of $b_{\mathrm{SOM}}$ without referring to observational datasets, however, may result in large uncertainties in land surface simulations.

In this study, we propose to estimate the $b$ values using soil water retention curve data of soil samples from the nine stations in the Naqu region. It is noteworthy that instead of employing commonly used cost functions (e.g., the cost function that quantifies the difference between simulated and observed soil water contents) to determine an optimal $b$ value, the empirical Eq. (14) is transformed to obtain a linear relationship between soil water content $(\theta)$ and water potential $(\psi)$, and then the $b$ value can be obtained through a linear fit. The specific steps are as follows.

First, take the logarithm of both sides of Eq. (14) and then convert it into Eq. (15), so that $\ln \psi$ and $\ln \theta-\ln \theta_{s}$ meet a linear relationship. Let $y=\ln \psi$ and $x=\ln \theta-\ln \theta_{s}$, then Eq. (15) can be rewritten as Eq. (16). Figure 5a presents three typical soil water retention curves selected from observations, indicating that there are obvious differences among soils with various SOM contents. Second, the sample data are fitted linearly to Eq. (16), and the absolute slope value of the fitting line is the corresponding $b$ value. As shown in Fig. 5b, the SR06 and LS08 schemes evidently underestimate observed $b$ values. Thus, we further recalculate the $b_{\text {SOM }}$ based on Eqs. (7)-(8) using the fitted $b$ value.

$$
\begin{aligned}
\psi(\theta) & =\psi_{s}\left(\theta / \theta_{s}\right)^{-b}, \\
\ln \psi & =\ln \psi_{s}-b\left(\ln \theta-\ln \theta_{s}\right), \quad \text { and } \\
y & =-b x+\ln \psi_{s},
\end{aligned}
$$

As shown in Fig. 5c, when the SOM content exceeds 6\%, the $b_{\text {SOM }}$ values derived from observations are stable and much larger than that $\left(b_{\mathrm{SOM}}=2.7\right)$ in Lawrence and Slater (2008). But when the SOM content is at a lower level, a large variation is seen among those observation-based $b_{\mathrm{SOM}}$, which is because that the effect of $b_{\text {SOM }}$ on $b$ value is negligible in 

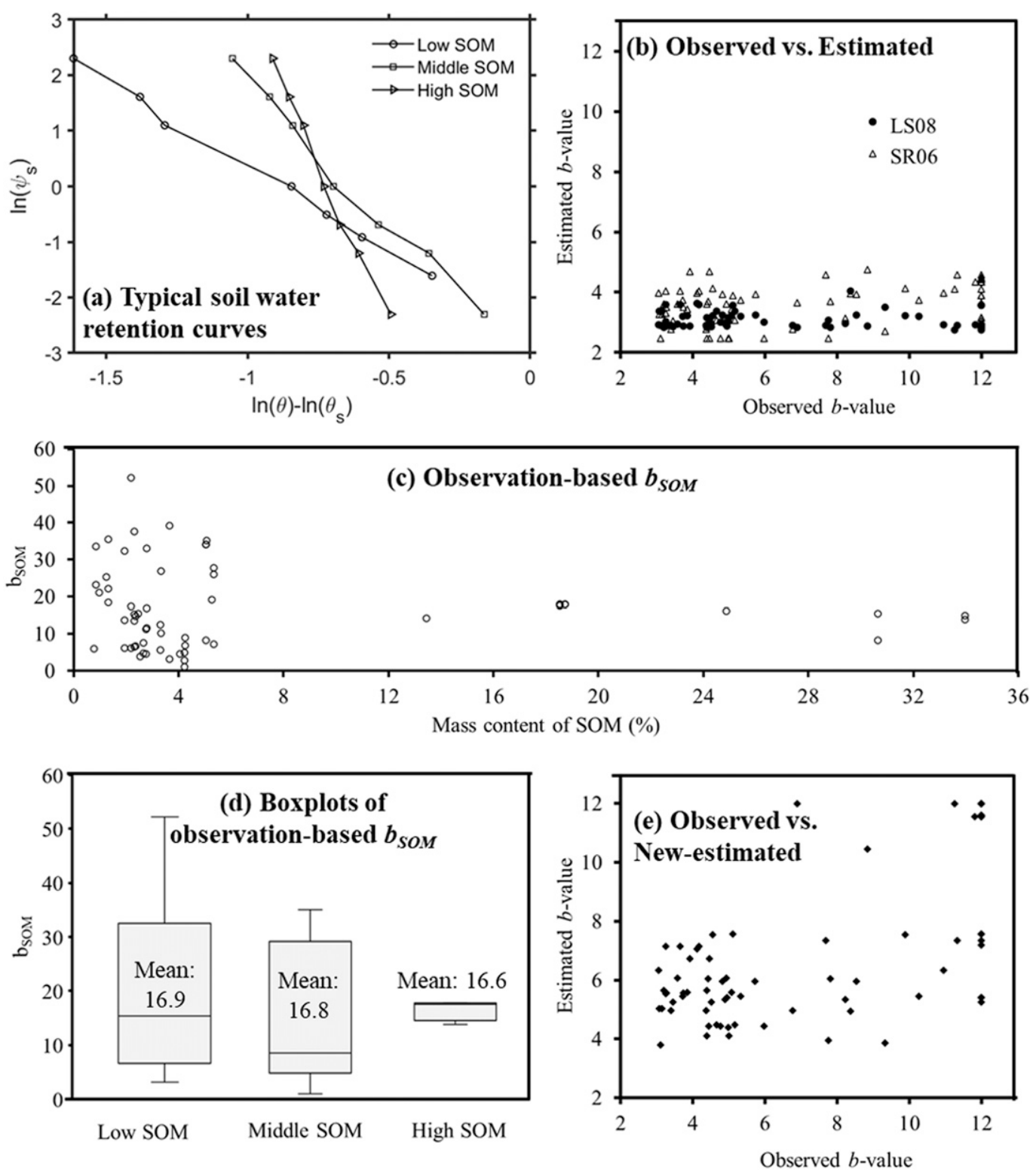

FIG. 5. (a) Three typical soil water retention curves. (b) Comparisons of observed and estimated values of the parameter $b$ calculated by SR06 and LS08 schemes. (c) The values of observation-based parameter $b_{\text {SOM }}$ for unfrozen soils. (d) Boxplots of these observation-based $b_{\text {SOM }}$ values. The black horizontal line inside the gray shaded box indicates the median value, top and bottom of the gray shaded box indicate 25 th and 75 th percentiles, and edges of the top and bottom whiskers indicate maximum and minimum values, respectively. (e) Comparisons of observed and estimated values of the parameter $b$ calculated by Eq. (7) with the new $b_{\text {SOM }}$ value.

this case. By contrast, for high SOM content, the $b$ parameter highly depends on $b_{\mathrm{SOM}}$ and thus the $b_{\mathrm{SOM}}$ estimates are more stable. Figure $5 \mathrm{~d}$ presents boxplots of these $b_{\text {SOM }}$ values for soils with different SOM contents. It is evident that for soils with high SOM content, the $b_{\text {SOM }}$ value is stable with a mean value of 16.6. This value is also larger than the one used by Zheng et al. (2015a) for Maqu, which may affect soil liquid water content simulations. We test the ability of the new $b_{\text {SOM }}$ value (16.6) in estimating the parameter $b$ with the fitted $b$ values as truth and find that there occurs an evident improvement (Fig. 5e) compared with LS08 and SR06 schemes. This indicates that the SOM in the TP differs from that in the Arctic. The larger $b_{\text {SOM }}$ value for TP soils may be explained by the higher degree of organic matter humification and the presence of a large number of roots in comparison to Arctic soils.

It should be noted that the soil water retention curves were measured in summer, so it is not guaranteed that the above derived $b_{\text {SOM }}$ value is applicable to frozen soils. Sun et al. (2016) found that soil moisture simulations using different SOM datasets differed mostly in summer and least 

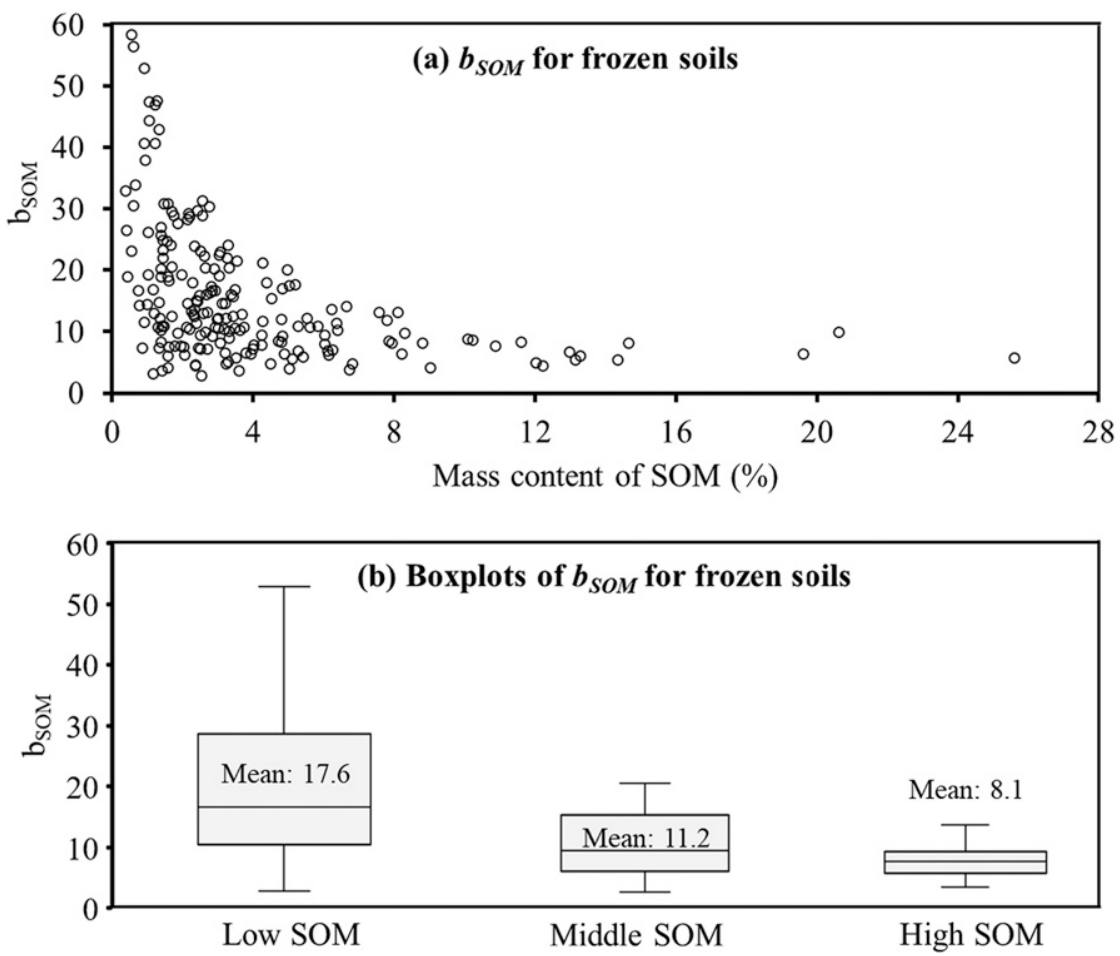

FIG. 6. (a) The values of observation-based parameter $b_{\text {SOM }}$ for frozen soils. (b) Boxplots of these observation-based $b_{\text {SOM }}$ values. The black horizontal line inside the gray shaded box indicates the median value, top and bottom of the gray shaded box indicate 25 th and 75 th percentiles, and edges of the top and bottom whiskers indicate maximum and minimum values, respectively.

in winter. Zheng et al. (2017) set a new limit (3.5-4.0) on the parameter $b$ at very low temperature conditions, which was proved to better capture the liquid water content in frozen soils than the default one (5.5) in the Noah LSM. These results imply that soil freezing may change the SOM effect on the parameter $b$. Therefore, it makes sense to use the soil temperature/moisture, soil texture, and organic matter content data observed at the 56 stations in the Naqu region to inversely derive the $b_{\text {SOM }}$ for frozen soils. The derivation is shown below.

When soil temperature $T<T_{f}(273.16 \mathrm{~K}$, freezing point), soil matrix potential $\psi(T)$ is defined as a function of $T$ :

$$
\psi(T)=\frac{10^{3} L_{f}\left(T-T_{f}\right)}{g T},
$$

Meanwhile, $\psi(T)$ can also be derived through

$$
\psi(T)=\psi_{s}\left(\frac{\theta_{l}}{\theta_{s}}\right)^{-b},
$$

where $L_{f}$ is the latent heat of fusion $\left(0.3336 \times 10^{6} \mathrm{~J} \mathrm{~kg}^{-1}\right), g$ is the gravitational acceleration $\left(9.8 \mathrm{~m} \mathrm{~s}^{-1}\right)$, and $\theta_{l}$ is the soil liquid water content $\left(\mathrm{m}^{3} \mathrm{~m}^{-3}\right)$. Since soil temperature is a known variable, $\psi(T)$ can be calculated by Eq. (17), and $\theta_{s}$ and $\psi_{s}$ can be calculated through Eqs. (5)-(6) and (9)-(10). Then the $b$ value can be inversely retrieved by Eq. (18) with observed soil liquid water content. It is found that the estimated $b$ value is nonsensitive to soil temperature (not shown).
Once the $b$ values are estimated, the LS08 scheme is utilized to derive the $b_{\text {SOM }}$ values, as shown in Fig. 6 a. Figure $6 \mathrm{~b}$ further presents boxplots of these observation-based $b_{\text {SOM }}$ values for soils with different SOM contents. It is clear that the $b_{\text {SOM }}$ value tends to be stable with the increase of SOM content. For soils with high SOM content, the $b_{\mathrm{SOM}}$ value roughly varies from 4 to 14 with a mean value of 8.1 , which is significantly less than that observed for unfrozen soils (Fig. 5d) and insensitive to small changes in the soil temperature range (not shown). The above results confirm our speculation that the $b_{\text {SOM }}$ values of unfrozen and frozen soils are different. This difference may be a result of the imperfection of the unfrozen water theory. Owing to the lack of observations, this issue is not further explored in this study but will likely be addressed in future research.

\section{2) OBSERVED SOM SATURATED HYDRAULIC CONDUCTIVITY}

Saturated hydraulic conductivity is one of the key soil properties and an important parameter to study soil permeability and water movement. Figure 7 a compares observed and estimated values of soil saturated hydraulic conductivity $\left(K_{s}\right)$ calculated by SR06 and LS08 schemes. It can be seen that these two schemes greatly overestimate the $K_{s}$ values, and this overestimation becomes more and more evident with increasing SOM content. We inversely derive the parameter $K_{s, \text { SOM }}$ based on Eqs. (11)-(12) using observed $K_{s}$ values. The corresponding $K_{s, \text { som values for soil }}$ samples are shown in Fig. 7b. When the SOM content 

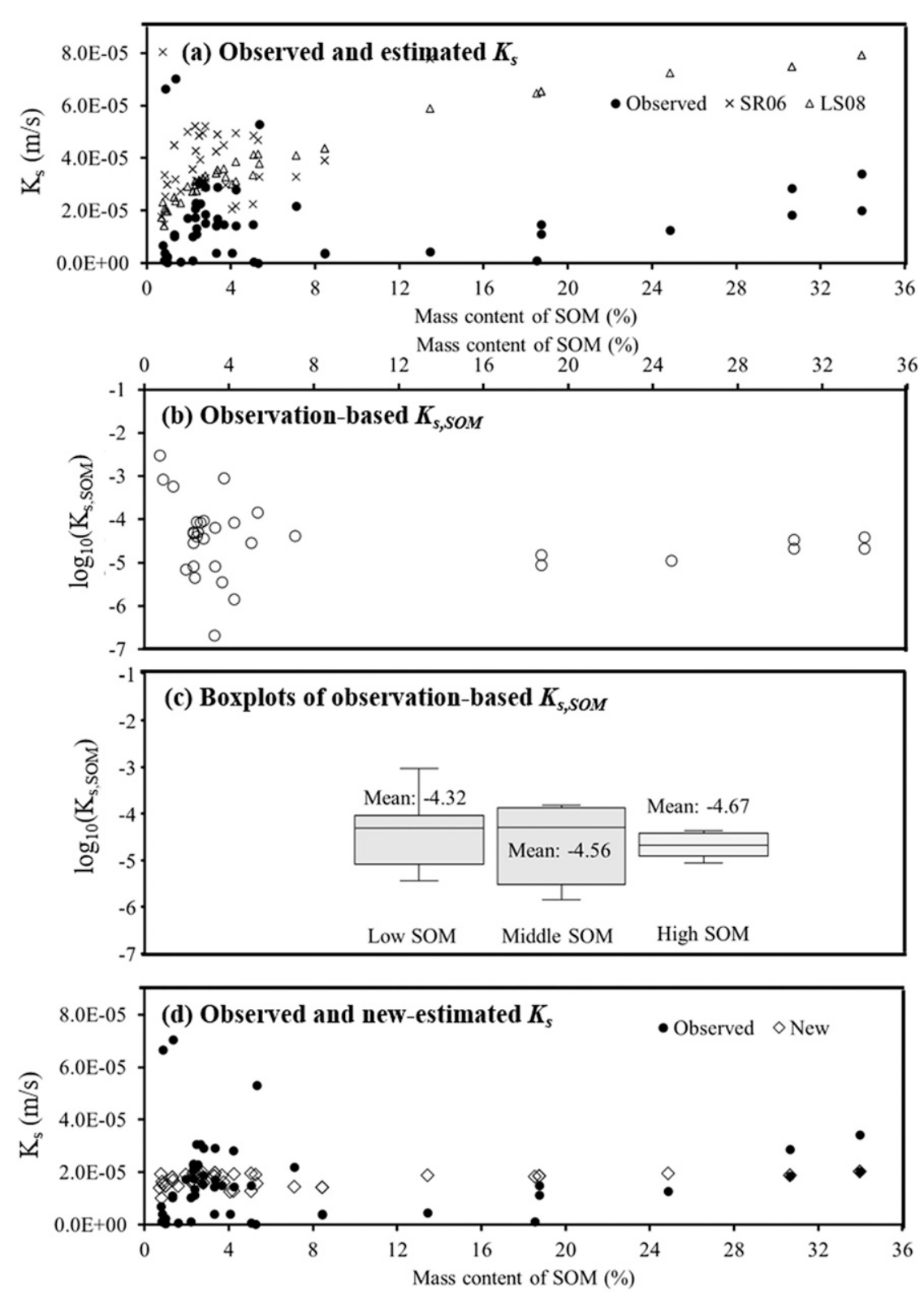

FIG. 7. (a) Comparisons of observed and estimated values of soil saturated hydraulic conductivity $\left(K_{s}\right)$ calculated by SR06 and LS08 schemes. (b) The values of observation-based SOM saturated hydraulic conductivity $\left(K_{s, \mathrm{SOM}}\right)$. (c) Boxplots of these observation-based $K_{s, \mathrm{SOM}}$ values. The black horizontal line inside the gray shaded box indicates the median value, top and bottom of the gray shaded box indicate 25th and 75th percentiles, and edges of the top and bottom whiskers indicate maximum and minimum values, respectively. (d) Comparisons of observed and estimated values of the parameter $K_{s}$ calculated by Eq. (11) with the new $K_{s, \text { SOM value. }}$

exceeds $6 \%$, the $K_{s, \text { som }}$ value is stable with a mean value of $10^{-4.67} \mathrm{~m} \mathrm{~s}^{-1}$ (Fig. 7c), which is less than the value adopted by LS08 scheme. When the SOM content is below $6 \%$, however, the $K_{s, \text { som }}$ value fluctuates a lot. Figure $7 \mathrm{~d}$ compares the calculated $K_{s}$ values using the new $K_{s, \text { som }}$ value in Eq. (11) with the observed ones. It can be clearly seen that the new $K_{s, \text { SOM }}$ value mitigates the overestimation of soil saturated hydraulic conductivity caused by LS08 and SR06 schemes.

Therefore, based on those observations, a new soil hydraulic scheme (NEWH) is proposed by modifying values of $b_{\text {SOM }}$ and $K_{s, \text { SOM }}$ in the LS08 scheme. In the NEWH scheme, for soils with high SOM content the $b_{\text {SOM }}$ value is set as 16.6 when soil temperature exceeds $0^{\circ} \mathrm{C}$, but 8.1 when the temperature is 

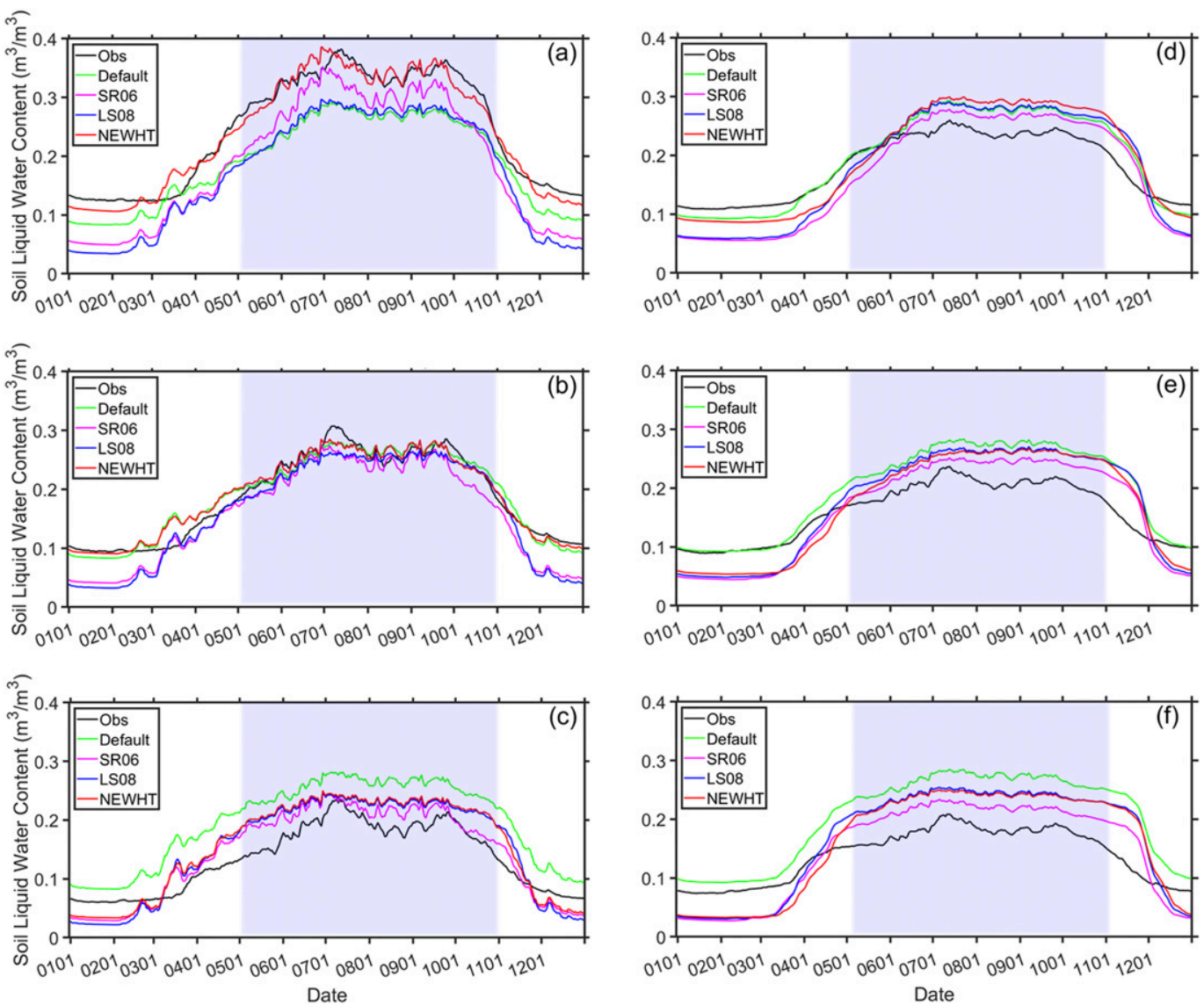

FIG. 8. Seasonal variations of the observed and simulated multiyear mean (2011-17) (left) surface (0-10 cm) and (right) subsurface $(10-40 \mathrm{~cm})$ soil liquid water content produced by four Noah-MP numerical experiments for the 56 soil moisture/temperature stations divided into three classes: (a),(d) high, (b),(e) middle, and (c),(f) low according to mass content of SOM.

below $-5^{\circ} \mathrm{C}$. To avoid a sudden change of $b_{\mathrm{SOM}}$, the value is assumed to decay linearly from 16.6 to 8.1 with soil temperature varying between $0^{\circ}$ and $-5^{\circ} \mathrm{C}$. Besides, the $K_{s, \text { som value is }}$ set as $10^{-4.67} \mathrm{~m} \mathrm{~s}^{-1}$. Under the same climate condition, the decomposition/humification degree of SOM, which affects its hydraulic properties, might be positively correlated with its mass content. Thus, for soils with SOM content not exceeding $2 \%$, the values of $b_{\text {SOM }}$ and $K_{s, \text { SOM }}$ are set as 2.7 and $2.8 \times$ $10^{-4} \mathrm{~m} \mathrm{~s}^{-1}$ according to Letts et al. (2000). For soils with SOM content between $2 \%$ and $6 \%$, it is assumed that the $b_{\text {SOM }}$ value increases linearly from 2.7 to 16.6 with the SOM content, while the $\log _{10}\left(K_{s, \text { SOM }}\right)$ value decreases linearly from $\log _{10}(2.8 \times$ $\left.10^{-4}\right)$ to -4.67 .

\section{Validation of the new soil hydraulic scheme with the Noah-MP}

\section{a. Designed experiments}

To investigate the influence of different soil hydraulic schemes (without and with considering SOM) on soil liquid water content simulations, four numerical experiments are conducted with a model time step of $1 \mathrm{~h}$ at the 56 soil moisture/temperature stations.

The first experiment (Default) is performed with the default soil option (Default scheme) in Noah-MP. As mentioned above, this scheme does not consider the impacts of SOM and directly sets values of soil hydraulic parameters according to the soil type. The first experiment serves as a reference for the others, reflecting the SOM impacts on simulated results. Other experiments explore the applicability of the consideration of SOM in different schemes. The second experiment (SR06) makes use of the Noah-MP alternative option (SR06 scheme), which takes into account the effects of soil texture and organic matter content on soil hydraulic parameters at different depths. For the third experiment (LS08), the LS08 scheme is utilized to replace the SR06 one in Noah-MP.

The fourth experiment (NEWHT) adopts the NEWH scheme with considering impacts of SOM on soil thermal parameters. Chen et al. (2012) studied the SOM effects on soil thermal properties using observations in the Naqu region and improved estimations of soil thermal conductivity and heat capacity. Furthermore, Luo et al. (2017) found that after introducing SOM and gravels based on the schemes proposed 
TABLE 2. Error statistics computed between the measured and simulated multiyear mean (2011-17) daily surface soil liquid water content produced by the Noah-MP Default, SR06, LS08, and NEWHT numerical experiments at stations with high surface SOM content.

\begin{tabular}{llcccc}
\hline \hline & & Default & SR06 & LS08 & NEWHT \\
\hline $\mathrm{MB}\left(\mathrm{m}^{3} \mathrm{~m}^{-3}\right)$ & Warm & -0.074 & -0.046 & -0.070 & -0.003 \\
& Cold & -0.033 & -0.063 & -0.072 & -0.004 \\
& Whole & -0.054 & -0.054 & -0.071 & -0.003 \\
$\mathrm{RMSE}\left(\mathrm{m}^{3} \mathrm{~m}^{-3}\right)$ & Warm & 0.075 & 0.050 & 0.071 & 0.016 \\
& Cold & 0.038 & 0.065 & 0.076 & 0.017 \\
& Whole & 0.060 & 0.058 & 0.074 & 0.017 \\
$R$ & Warm & 0.90 & 0.91 & 0.89 & 0.90 \\
& Cold & 0.87 & 0.92 & 0.88 & 0.92 \\
& Whole & 0.98 & 0.99 & 0.98 & 0.99 \\
\hline
\end{tabular}

by Chen et al. (2012) into Community Land Model (CLM4.5), soil temperature simulations at Zoige and Madoi stations located in the eastern TP were much better, consequently improving soil liquid water content simulations. Given the strong hydrothermal interactions, therefore, the NEWHT experiment considers SOM in the soil hydrothermal schemes. The used thermal scheme is as described in Chen et al. (2012).

\section{b. Evaluation of soil liquid water content simulations}

Figure 8 presents the simulated values of soil liquid water content obtained by four Noah-MP experiments. Compared with the observations, the first two experiments with optional schemes (Default and SR06) in Noah-MP underestimate surface soil liquid water content at stations with high surface SOM content. The simulated surface soil liquid water content in the SR06 experiment is higher in the warm season but lower in the cold season than that in the Default one (Fig. 8a). Throughout the year, both experiments overestimate the liquid water content at stations with low surface SOM content (Fig. 8c), while they perform relatively well at stations with middle surface SOM content (Fig. 8b). Regardless of stations with high or low surface SOM content, the SR06 experiment produces an obvious underestimation of surface soil liquid water content in the cold season, while the underestimation in the Default experiment gradually disappears or even turns to an overestimation with the decrease of the surface SOM content (Figs. 8a-c).

The major reason that the Default experiment underestimates the surface soil liquid water content at stations with high surface SOM content can be reasonably interpreted that, the default soil hydraulic scheme does not take into account the role of organic matter, thus resulting in an underestimation of soil porosity. In the SR06 experiment, surface soil porosity estimations and soil moisture simulations at stations with high surface SOM content are improved to a certain extent in the warm season, which is attributed to the consideration of SOM. On the whole, the SR06 experiment captures surface soil liquid water content better than the Default one in the warm season, while worse in the cold season.

As shown in Figs. 8a,b, the NEWHT experiment generally exhibits the best performance for surface soil liquid water. Compared with the Default, SR06, and LS08 ones, the NEWHT
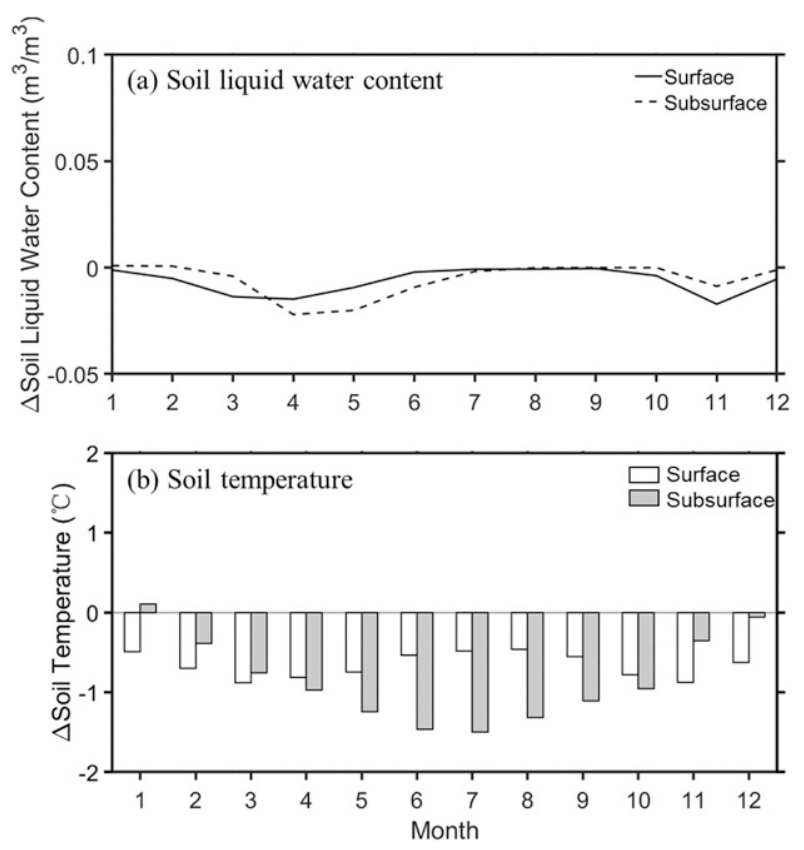

FIG. 9. Differences in multiyear mean (2011-17) (a) soil liquid water content and (b) temperature simulations of the NEWHT and NEWH numerical experiments (the former minus the latter) for stations with high mass content of surface SOM.

experiment significantly improves the simulation of surface soil liquid water content in both the cold and warm seasons, especially at stations with high surface SOM content. Liu et al. (2012) and Luo et al. (2020) found that the spatial distributions of soil moisture and organic carbon in the TP were similar, that is, there was a positive correlation between soil moisture and organic matter content. Both the NEWHT and SR06 experiments capture this distribution well, but the Default and LS08 ones cannot.

All the four experiments perform poorly in subsurface soil liquid water. The patterns (Figs. 8d-f) are similar to those in the surface layer at stations with low surface SOM content (Fig. 8c) probably due to overall low subsurface SOM content, except for stations with high surface SOM content. The difference in Fig. 8d is probably because surface soil liquid water content simulations inevitably affect the water content in the deeper layer. In addition, subsurface soil liquid water content simulations are generally overestimated in the warm season. This may be related to the apparent stratification of surface and subsurface soils, which results from abundance roots and causes discontinuities in thermal and hydrological properties that are difficult to be handled in the model. A possible solution to remediate the overestimation in subsurface soil water content is to revise the vertical root distribution, as demonstrated in Zheng et al. (2015a).

Tables 2 and S2 present the error statistics computed between the measured and simulated multiyear mean (2011-17) daily liquid water content in the surface soil layer produced by the Default, SR06, LS08, and NEWHT numerical experiments. For stations with high surface SOM content (Table 2), the NEWHT experiment reduces the mean bias (MB) and 

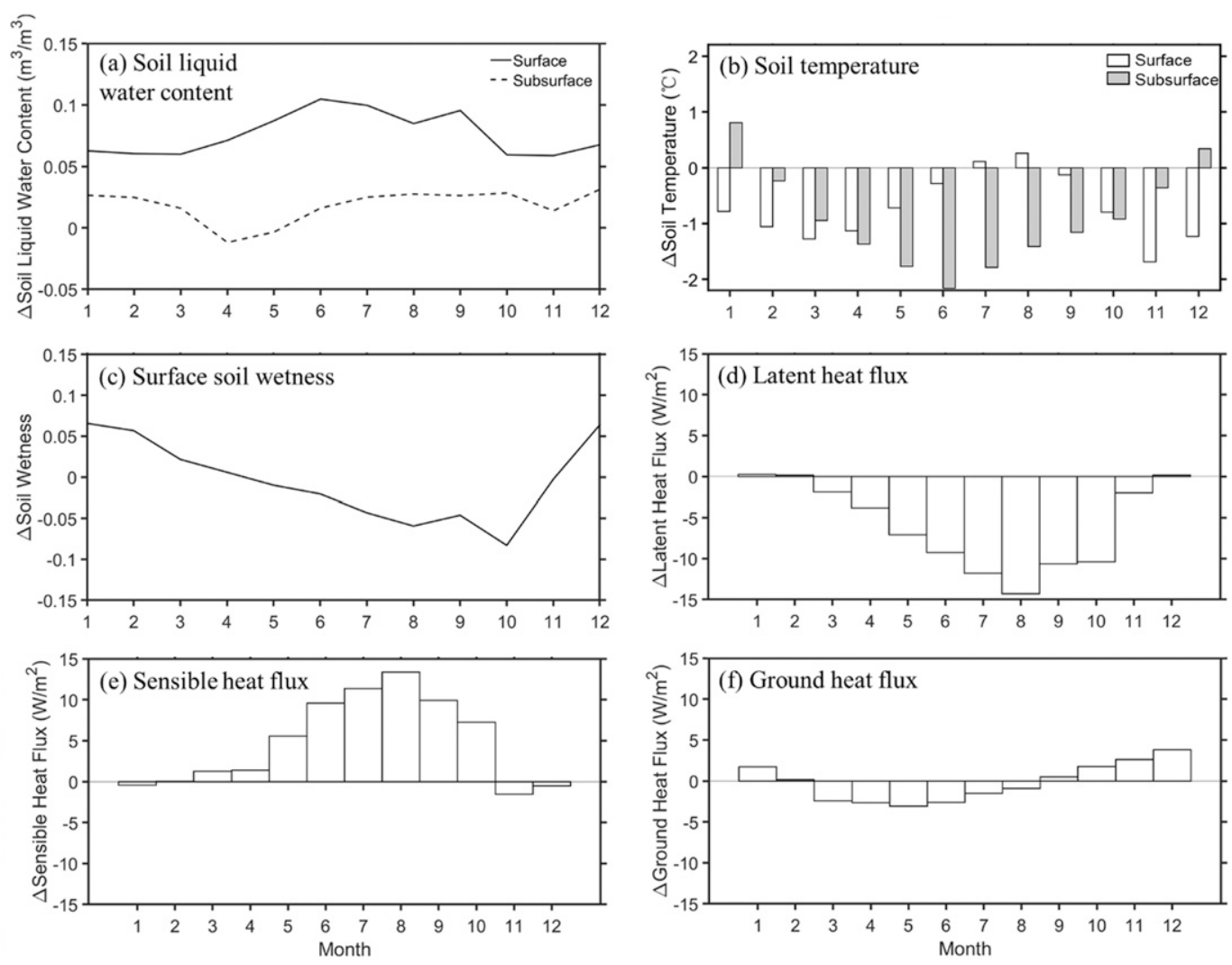

FIG. 10. Differences in multiyear mean (2011-17) soil (a) liquid water content and (b) temperature, (c) surface soil wetness, (d) latent heat flux, (e) sensible heat flux, and (f) ground heat flux simulations between the NEWHT and NEWHT0 experiments (the former minus the latter) for stations with high mass content of surface SOM.

root-mean-square error (RMSE) by $95.9 \%$ and $78.7 \%$ in the warm season $(87.9 \%$ and $55.3 \%$ in the cold season) in comparison to the Default one. And the correlation coefficient $(R)$ is about the same for the four experiments. As shown in Table S2, for stations with middle surface SOM content, both the Default and NEWHT experiments perform well. But for stations with low surface SOM content, the NEWHT, LS08, and SR06 experiments outperform the Default one. In terms of error statistics, this study has achieved more significant improvements in Naqu than those of Zheng et al. (2015a) in Maqu. Overall, the NEWHT experiment can greatly improve the surface liquid water content simulations for soils with high surface SOM content.

\section{c. Impact of SOM hydrothermal properties on soil state}

In this section, we distinguish the different effects of SOM hydrothermal properties on soil state. The NEWH experiment just employs the NEW hydraulic scheme without considering SOM effects on soil thermal properties. As shown in Fig. 9a, differences in simulated soil liquid water content between the NEWH and NEWHT experiments are small with relatively large differences during the freezing-thawing period (March-May and November). Thus, the SOM thermal properties have overall little influence on soil liquid water content, and the improved liquid water content simulations shown in Fig. 8 are mainly attributed to the new soil hydraulic scheme.

Figure $9 \mathrm{~b}$ indicates that SOM thermal properties can lower simulated soil temperature almost throughout the year. For surface soil temperature, the cooling effect is strongest in March and November, which corresponds with the largest difference in soil liquid water (Fig. 9a). But for subsurface soil temperature, SOM thermal properties exert a more evident cooling effect in the warm season than in the cold season. This is mainly because subsurface soil temperature is affected by both surface soil temperature and thermal properties. After considering the SOM thermal properties, the combination of lower surface soil temperature, increased heat capacity and decreased thermal conductivity of the soil makes it more difficult for heat from the surface to reach the deeper layer, thus resulting in a much significant decrease in subsurface soil temperature in the warm season. In the cold season, since heat is mainly transferred from the bottom to the top in soils, changes in subsurface soil temperature are significantly smaller than those in the warm season.

Since SOM has an obvious cooling effect and thus acts as a protector of frozen soils, the liquid water content simulations of the NEWHT experiment are reduced to some extent during the freezing-thawing period compared with those of the NEWH one. Given the above, it is suggested that not 
considering SOM thermal properties in the model would cause excessive and rapid degradation of simulated frozen soils.

\section{Discussion on the role of SOM with the revised Noah-MP}

The aforementioned results confirm that the new soil hydraulic scheme can well capture the variation of soil liquid water content with SOM content when compared with the other three schemes. In the following, we perform the NEWHT experiment with the SOM content artificially set to zero (taken as the NEWHT0 experiment), to further discuss the effects of SOM hydrothermal properties on soil state and land energy budget.

Figures 10a and 10b show differences in simulated soil liquid water content and temperature between the NEWHT and NEWHT0 experiments. Generally, considering SOM can significantly increase simulated surface and subsurface soil liquid water content (Figs. 10a). Regarding soil thermal state, as shown in Fig. 10b, the inclusion of SOM leads to surface soil temperature increase in July-August but decrease in the rest months. The effect on surface soil temperature is obvious in the cold season, but much weak or even negligible in the warm season. For subsurface soil temperature, however, the SOM hydrothermal properties impose different effects: an increase in December and January but a decrease occurs in the rest months. Moreover, the effect is more pronounced in the warm season than in the cold season. Overall, considering the influence of SOM can reduce simulated soil temperature.

These changes in soil hydrothermal state are closely related to land energy budget. Figures 10c-f compare surface soil wetness and land flux simulations of the NEWHT and NEWHT0 experiments. For soil wetness, the SOM effect is not always synchronized with that on soil liquid water content. This is mainly because soil wetness is determined by the ratio of soil liquid water content to soil porosity. Although considering SOM can increase soil liquid water content, it also enlarges the porosity and thus there may be an opposite change between soil wetness and liquid water content. As shown in Fig. 10c, surface soil wetness decreases obviously in the warm season, significantly reducing surface evaporation and thus latent heat flux (Fig. 10d) and enhancing sensible heat flux (Fig. 10e). Although soil wetness increases in winter, it has a negligible effect on evaporation due to the frozen ground during this period and thus little influence on sensible heat flux. It is noteworthy that the SOM effects on sensible and latent heat fluxes are greater in Naqu (Figs. 10d,e) than in Maqu (as shown in Zheng et al. 2015a), probably due to the fact that Naqu is located in a semiarid zone where evaporation is more sensitive to soil water.

As shown in Fig. 10f, ground heat flux exerts a decrease in spring and summer but an increase in autumn and winter after considering SOM. The variation in ground heat flux is determined by a combination of variations in surface soil thermal conductivity and temperature gradient between the ground and surface soil. The changes on both of the two factors are relatively complex. On the one hand, SOM can cause a decrease in surface soil thermal conductivity for dry soils, but an increase for wet soils. On the other hand, there are many factors that influence ground temperature because the ground is in direct contact with the atmosphere. Despite the complex variations, ground heat flux changes much less than latent and sensible heat fluxes.

Therefore, SOM can impose a great influence on land energy budget in the TP, which will further affect the water budget. The including of SOM in the new soil hydraulic scheme is found to decrease evaporation and may lead to decreased surface runoff but increased unground runoff. Furthermore, it tends to cause higher air temperature and less precipitation in climate models. Given that current models generally underestimate air temperature but overestimate precipitation over the TP (Mueller and Seneviratne 2014; Su et al. 2013), considering SOM may help to ameliorate these biases. The expected impacts will be carefully investigated in future studies. However, due to the fact that the degree of SOM decay may affect soil hydraulic properties as pointed out in Letts et al. (2000), the new scheme is not necessarily applicable to regions beyond the TP, where the impact of SOM is not yet clear.

\section{Conclusions}

Organic matter is an important component of soils in the central and eastern TP, yet its effects are poorly described in current LSMs. In this study, we investigate hydraulic properties of SOM through measured soil texture, organic matter content, soil water retention curve, saturated hydraulic conductivity, and soil moisture/temperature data in the Naqu region, central TP. Based on these observations, we find that the SOM pore-size distribution parameter $\left(b_{\mathrm{SOM}}\right)$ has a much larger value than the one in the literature. Moreover, observation-based SOM saturated hydraulic conductivity $\left(K_{s, \text { SOM }}\right)$ is smaller than the one used in the LS08 scheme. We then modified the LS08 soil hydraulic scheme using these observation-based values of $b_{\mathrm{SOM}}$ and $K_{s, \text { SOM }}$. Numerical experiments performed with the Noah-MP reveal that the new hydraulic scheme significantly improves the model's ability in soil liquid water content simulation in comparison to the original ones at stations with high surface SOM content, especially in the warm season. A further application with the revised Noah-MP indicates that the consideration of SOM high-water-holding capacity and thermal inertia can enhance sensible heat flux but decrease evaporation and subsurface soil temperature in the warm season and tends to have a much weak effect in the cold season. But for surface soil temperature, the SOM effect is much more obvious in the cold season than in the warm season. Our study provides a better understanding of SOM effects on soil heat and water flow, which will facilitate revealing energy and water cycle processes on the TP. However, it is important to note that there are many other factors at play and the new hydraulic parameterization is not necessarily applicable beyond the TP.

The full exploitation of the new soil hydraulic parameterization also depends on reliable regional or global soil texture and SOM content data, which are recognized as priorities for future work. There are several options of these 
gridded datasets. One is the latest global high-resolution soil datasets (e.g., Dai et al. 2019b). The other one can be the SOM content data inversely estimated by the model using long-term series soil moisture data (Luo et al. 2020). As mentioned above, an increase in SOM content may slow the degradation of frozen soils; conversely, a decrease in the content may accelerate the degradation. Therefore, further research on the spatial distribution of SOM needs to be vigorously pursued in the future.

Acknowledgments. This work was supported by National Basic Research Program of China (Grant 2018YFA0605400), NSFC Basic Research Center for Tibetan Plateau Earth System (Grant 41988101), and National Science Foundation of China (Grant 41975125).

Data availability statement. The soil moisture/temperature data are available at https://data.tpdc.ac.cn/en/data/6557f9ac-f752-474ea156-3cfc28434cad/. The global high-resolution soil composition data are available at http:/globalchange.bnu.edu.cn/research/soil5.jsp. The other measurements used in this study are provided by this team. For data access, please contact Yingying Chen (chenyy@itpcas.ac.cn).

\section{REFERENCES}

Brutsaert, W. A., 1982: Evaporation into the Atmosphere. D. Reidel, 299 pp.

Chen, Y., K. Yang, W. Tang, J. Qin, and L. Zhao, 2012: Parameterizing soil organic carbon's impacts on soil porosity and thermal parameters for eastern Tibet grasslands. Sci. China Earth Sci., 55, 1001-1011, https://doi.org/10.1007/s11430-012-4433-0.

$\longrightarrow,-$ J. Jin, L. Zhao, W. Tang, and M. Han, 2013: Evaluation of AMSR-E retrievals and GLDAS simulations against observations of a soil moisture network on the central Tibetan Plateau. J. Geophys. Res. Atmos., 118, 4466-4475, https://doi.org/10.1002/jgrd.50301.

Clapp, R. B., and G. M. Hornberger, 1978: Empirical equations for some soil hydraulic properties. Water Resour. Res., 14, 601604, https://doi.org/10.1029/WR014i004p00601.

Cosby, B. J., G. M. Hornberger, R. B. Clapp, and T. R. Ginn, 1984: A statistical exploration of the relationships of soil moisture characteristics to the physical properties of soils. Water Resour. Res., 20, 682-690, https://doi.org/10.1029/WR020i006p00682.

Dai, Y., N. Wei, H. Yuan, S. Zhang, W. Shangguan, S. Liu, and X. Lu, 2019a: Evaluation of soil thermal conductivity schemes for use in land surface modelling. J. Adv. Model. Earth Syst., 11, 3454-3473, https://doi.org/10.1029/2019MS001723.

— , and Coauthors, 2019b: A global high-resolution data set of soil hydraulic and thermal properties for land surface modeling. J. Adv. Model. Earth Syst., 11, 2996-3023, https://doi.org/ 10.1029/2019MS001784.

—, T. Yao, L. Wang, X. Li, and X. Zhang, 2020: Contrasting roles of a large Alpine lake on Tibetan Plateau in shaping regional precipitation during summer and autumn. Front. Earth Sci., 8, 358, https://doi.org/10.3389/feart.2020.00358.

FAO, 1971: South America. Vol. IV, Soil Map of the World (1:5,000,000), UNESCO, 193 pp., http://www.fao.org/3/as361e/ as361e.pdf.

- 1974: Legend. Vol. I, Soil Map of the World (1:5,000,000), UNESCO, 59 pp., http://www.fao.org/3/as360e/as360e.pdf.

_ $1975 \mathrm{a}$ : North America. Vol. II, Soil Map of the World (1:5,000,000), UNESCO, 210 pp., http://www.fao.org/3/as359e/ as359e.pdf.
_ 1975b: Mexico and Central America. Vol. III, Soil Map of the World (1:5,000,000), UNESCO, 96 pp., http://www.fao.org/3/ as358e/as358e.pdf.

_- 1977a: Africa. Vol. VI, Soil Map of the World (1:5,000,000), UNESCO, 340 pp., http://www.fao.org/3/as357e/as357e.pdf.

__, 1977b: South Asia. Vol. VII, Soil Map of the World (1:5,000,000), UNESCO, 144 pp., http://www.fao.org/3/as352e/ as352e.pdf.

_- 1978a: North and Central Asia. Vol. VIII, Soil Map of the World (1:5,000,000), UNESCO, 180 pp., http://www.fao.org/3/ as356e/as356e.pdf.

, 1978b: Australasia. Vol. X, Soil Map of the World (1:5,000,000). UNESCO, 236 pp., http://www.fao.org/3/as355e/as355e.pdf.

—, 1979: Southeast Asia. Vol. IX, Soil Map of the World (1:5,000,000) UNESCO, 179 pp., http://www.fao.org/3/as353e/ as353e.pdf.

_- 1981: Europe. Vol. V, Soil Map of the World (1:5,000,000), UNESCO, 225 pp., http://www.fao.org/3/as354e/as354e.pdf.

_ 1991: The digitized soil map of the world. World Soil Resources Rep. 67, accessed 16 April 2019, https://data.apps.fao.org/map/ catalog/srv/eng/catalog.search\#/home.

Gao, Y., K. Li, F. Chen, Y. Jiang, and C. Lu, 2015: Assessing and improving Noah-MP land model simulations for the central Tibetan Plateau. J. Geophys. Res., 120, 9258-9278, https:// doi.org/10.1002/2015JD023404.

He, J., K. Yang, W. Tang, H. Lu, J. Qin, Y. Chen, and X. Li, 2020: The first high-resolution meteorological forcing dataset for land process studies over China. Sci. Data, 7, 25, https:// doi.org/10.1038/s41597-020-0369-y.

Jarvis, P. G., 1976: The interpretation of the variations in leaf water potential and stomatal conductance found in canopies in the field. Philos. Trans. Roy. Soc., B273, 593-610, https://doi.org/ 10.1098/rstb.1976.0035.

Koike, T., 2004: The coordinated enhanced observing period-An initial step for integrated global water cycle observation. WMO Bull., 53, 115-121.

Lawrence, D. M., and A. G. Slater, 2008: Incorporating organic soil into a global climate model. Climate Dyn., 30, 145-160, https:// doi.org/10.1007/s00382-007-0278-1.

Letts, M. G., N. T. Roulet, N. T. Comer, M. R. Skarupa, and D. L. Verseghy, 2000: Parametrization of peatland hydraulic properties for the Canadian land surface scheme. Atmos.-Ocean, 38, 141-160, https://doi.org/10.1080/07055900.2000.9649643.

Liu, W., and Coauthors, 2012: Storage, patterns, and control of soil organic carbon and nitrogen in the northeastern margin of the Qinghai-Tibetan Plateau. Environ. Res. Lett., 7, 35401-35412, https://doi.org/10.1088/1748-9326/7/3/035401.

Luo, Q., K. Yang, Y. Chen, and X. Zhou, 2020: Method development for estimating soil organic carbon content in an alpine region using soil moisture data. Sci. China Earth Sci., 63, 591601, https://doi.org/10.1007/s11430-019-9554-8.

Luo, S., X. Fang, S. Lyu, Y. Zhang, and B. Chen, 2017: Improving CLM4.5 simulations of land-atmosphere exchange during freeze-thaw processes on the Tibetan Plateau. J. Meteor. Res., 31, 916-930, https://doi.org/10.1007/s13351-017-6063-0.

Ma, Y. M., S. C. Kang, L. P. Zhu, B. Q. Xu, L. D. Tian, and T. D. Yao, 2008: Tibetan Observation and Research Platform: Atmosphere-land interaction over a heterogeneous landscape. Bull. Amer. Meteor. Soc., 89, 1487-1492, https://doi.org/ 10.1175/2008BAMS2545.1.

Mueller, B., and S. I. Seneviratne, 2014: Systematic land climate and evapotranspiration biases in CMIP5 simulations. Geophys. Res. Lett., 41, 128-134, https://doi.org/10.1002/2013GL058055. 
Niu, G.-Y., and Z.-L. Yang, 2006: Effects of frozen soil on snowmelt runoff and soil water storage at a continental scale.J. Hydrometeor., 7, 937-952, https://doi.org/10.1175/JHM538.1.

,-- , R. E. Dickinson, L. E. Gulden, and H. Su, 2007: Development of a simple groundwater model for use in climate models and evaluation with Gravity Recovery and Climate Experiment data. J. Geophys. Res., 112, D07103, https://doi.org/10.1029/2006JD007522.

— , and Coauthors, 2011: The community Noah land surface model with multiparameterization options (Noah-MP): 1. Model description and evaluation with local-scale measurements. J. Geophys. Res., 116, D12109, https://doi.org/10.1029/ 2010JD015139.

Oleson, K. W., and Coauthors, 2004: Technical description of the Community Land Model (CLM). NCAR Tech. Note NCAR/TN461+STR, 174 pp., https://www.cgd.ucar.edu/tss/clm/distribution/ clm3.0/TechNote/CLM_Tech_Note.pdf.

Saxton, K. E., and W. J. Rawls, 2006: Soil water characteristic estimates by texture and organic matter for hydrologic solutions. Soil Sci. Soc. Amer. J., 70, 1569-1578, https://doi.org/10.2136/sssaj2005.0117.

Shangguan, W., Y. Dai, Q. Duan, B. Liu, and H. Yuan, 2014: A global soil data set for earth system modeling. J. Adv. Model. Earth Syst., 6, 249-263, https://doi.org/10.1002/2013MS000293.

Su, F., X. Duan, D. Chen, Z. Hao, and L. Cuo, 2013: Evaluation of the global climate models in the CMIP5 over the Tibetan Plateau. J. Climate, 26, 3187-3208, https://doi.org/10.1175/ JCLI-D-12-00321.1.

Sun, J., K. Yang, W. Guo, Y. Wang, J. He, and H. Lu, 2020: Why has the inner Tibetan Plateau become wetter since the mid-1990s? J. Climate, 33, 8507-8522, https://doi.org/10.1175/JCLI-D-19-0471.1.

Sun, S., and Coauthors, 2016: Improving soil organic carbon parameterization of land surface model for cold regions in the northeastern Tibetan Plateau, China. Ecol. Modell., 330, 1-15, https://doi.org/10.1016/j.ecolmodel.2016.03.014.

Verseghy, D. L., 1991: CLASS-A Canadian land surface scheme for GCMS: I. Soil model. Int. J. Climatol., 11, 111-133, https:// doi.org/10.1002/joc.3370110202.

Yang, K., and J. He, 2011: China meteorological forcing dataset (1979-2015). National Tibetan Plateau Data Center, accessed 19 March 2019, https://doi.org/10.3972/westdc.002.2014.db.
— T. Koike, B. Ye, and L. Bastidas, 2005: Inverse analysis of the role of soil vertical heterogeneity in controlling surface soil state and energy partition. J. Geophys. Res., 110, D08101, https://doi.org/10.1029/2004JD005500.

_- Y. Y. Chen, and J. Qin, 2009: Some practical notes on the land surface modeling in the Tibetan Plateau. Hydrol. Earth Syst. Sci., 13, 687-701, https://doi.org/10.5194/hess13-687-2009.

—_, and Coauthors, 2013: A multiscale soil moisture and freezethaw monitoring network on the third pole. Bull. Amer. Meteor. Soc., 94, 1907-1916, https://doi.org/10.1175/BAMS-D12-00203.1.

Zhang, G., Y. Chen, and J. Li, 2021: Effects of organic soil in the Noah-MP land-surface model on simulated skin and soil temperature profiles and surface energy exchanges for China. Atmos. Res., 249, 105284, https://doi.org/10.1016/ j.atmosres.2020.105284.

Zhang, Y., M. G. Schaap, and Z. Wei, 2020: Development of hierarchical ensemble model and estimates of soil water retention with global coverage. Geophys. Res. Lett., 47, e2020GL088819, https://doi.org/10.1029/2020GL088819.

Zhao, L., and Coauthors, 2013: Spatiotemporal analysis of soil moisture observations within a Tibetan mesoscale area and its implication to regional soil moisture measurements. J. Hydrol., 482, 92-104, https://doi.org/10.1016/ j.jhydrol.2012.12.033.

Zheng, D., R. van der Velde, Z. Su, X. Wang, J. Wen, M. J. Booij, A. Y. Hoekstra, and Y. Chen, 2015a: Augmentations to the Noah model physics for application to the Yellow River source area. Part I: Soil water flow. J. Hydrometeor., 16, 26592676, https://doi.org/10.1175/JHM-D-14-0198.1.

,,,--- and $-2015 \mathrm{~b}$ : Augmentations to the Noah model physics for application to the Yellow River source area. Part II: Turbulent heat fluxes and soil heat transport. J. Hydrometeor., 16, 2677-2694, https://doi.org/10.1175/JHM-D-14-0199.1.

,,,--- J. Wen, X. Wang, and K. Yang, 2017: Evaluation of Noah frozen soil parameterization for application to a Tibetan meadow ecosystem. J. Hydrometeor., 18, 1749-1763, https://doi.org/10.1175/JHM-D-16-0199.1. 